\title{
ANALISIS TIANG PANCANG SEBAGAI DINDING PENAHAN TANAH DI DAERAH ALIRAN SUNGAI MENGGUNAKAN PROGRAM PYWALL
}

\author{
Amelinda Jocelin ${ }^{1}$ dan Chaidir Anwar Makarim ${ }^{2}$ \\ ${ }^{1}$ Program Studi Sarjana Teknik Sipil, Universitas Tarumanagara, Jl. Letjen S. Parman No.1 Jakarta \\ amelinda.325160078@stu.untar.ac.id \\ ${ }^{2}$ Program Studi Sarjana Teknik Sipil, Universitas Tarumanagara, J1. Letjen S. Parman No.1 Jakarta \\ chaidir259@gmail.com
}

Masuk: 13-07-2020, revisi: 25-07-2020, diterima untuk diterbitkan: 05-08-2020

\begin{abstract}
Construction failure may occur due to various things. One of them is used a shallow foundation for a retaining wall. It can possible, but consider environmental condition where there is a heavy flow of water along the wall. Therefore it is necessary to use a deep foundation. Pile are printed concrete products. It is used to support a load and distribute the load to the subgrade. This calculation is using a closed-form solution. The software used is $P$-Y Wall which fixes a flexible retaining wall or pile/drill wall. This program will calculate pile deflection, shear forces, and bending moments. In this assessment, variations were made relating to the distance between the piles and the values of L1 and L2. L1 shows the free long pile and L2 shows the long pile entering the ground. Variation $3 \mathrm{~A}$ with the distance between the piles $100 \mathrm{~cm}$ and the length of the pile $15 \mathrm{~m}$. The average value of L1 was $10.8 \mathrm{~m}$ for the value and the value of L2 was $4.2 \mathrm{~m}$. Both of deflection and moment can fulfill the qualification, the value is $9 \mathrm{~cm}(\max 10,8 \mathrm{~cm})$ and $320 \mathrm{kNm}(\max 399 \mathrm{kN} / \mathrm{m})$.
\end{abstract}

Keywords: retaining wall; pile; PYWALL; deflection; moment

\begin{abstract}
ABSTRAK
Kegagalan konstruksi mungkin saja terjaid karena berbagai hal. Salah satunya adalah digunakannya pondasi dangkal untuk dinding penahan tanah. Hal ini bukannya tidak mungkin dilakukan tapi mengingat kondisi lingkungan setempat dimana adanya aliran air yang cukup deras disepanjang dinding. Oleh karena itu perlu digunakannya pondasi dalam. Tiang beton adalah produk beton cetak. Tiang ini digunakan sebagai tiang untuk menyangga beban sekaligus menyalurkan beban ke dasar tanah. Tiang ini juga sudah dilengkapi dengan tulangan besi sehingga bisa menjaga mutu dan kekuatannya. Dalam perhitungan ini menggunakan closed-form solution. Software yang digunakan adalah P-Y Wall yang menganalisis perilaku dinding penahan yang fleksibel atau dinding tiang pancang/bor. Program ini akan menghitung defleksi dinding/tiang, gaya geser, dan momen lentur. Dalam penulisan ini dibuat variasi yang berhubungan dengan jarak antar tiang dan besarnya L1 dan L2. L1 menunjukkan panjang tiang bebas dan L2 menunjukkan panjang tiang yang masuk ke dalam tanah. Diambil variasi terbaik untuk desain dinding penahan tanah ini adalah Variasi 3A yaitu dengan jarak antar tiang $75 \mathrm{~cm}$ dan panjang tiang $15 \mathrm{~m}$. Artinya nilai L1 sebesar 10,8 m dan nilai L2 sebesar 4,2 m. Defleksi dan momen memenuhi syarat sebesar 9,1 cm (dari syarat 10,8 cm) dan $320 \mathrm{kNm}$ (maksimum $399 \mathrm{kN} / \mathrm{m}$ ).
\end{abstract}

Kata kunci: dinding penahan tanah; tiang; PYWALL; defleksi; momen

\section{PENDAHULUAN}

Peristiwa banjir yang membuka awal tahun 2020 meninggalkan berbagai kerusakan baik dalam skala kecil maupun besar. Salah satu kerusakan yang terjadi adalah runtuhnya dinding penahan tanah di kawasan Depok. Dinding penahan tanah tersebut terletak di tikungan jalan bersebelahan dengan sungai dan tercatat sudah 4 (empat) kali runtuh. Berbagai asumsi muncul terkait kegagalan ini, baik karena faktor alam maupun dari kegagalan desain yang tidak memperhatikan kondisi lingkungan di daerah yang bersangkutan. 


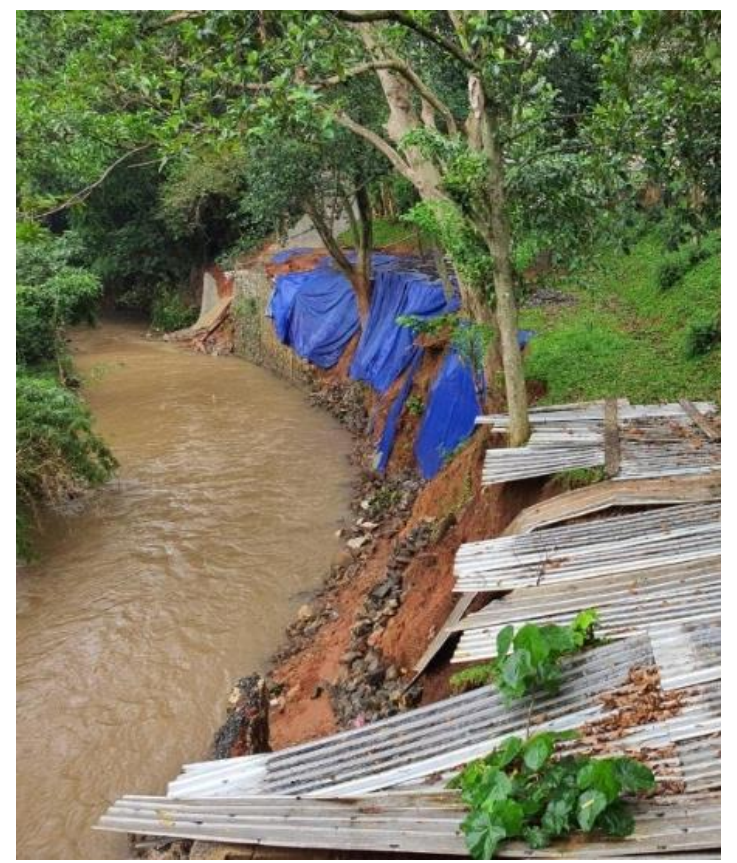

Gambar 1. Kondisi keruntuhan dinding penahan tanah

Kasus kegagalan seperti ini bukan yang pertama kali terjadi. Salah satunya adalah digunakannya pondasi dangkal untuk dinding penahan tanah. Hal ini bukannya tidak mungkin dilakukan tapi mengingat kondisi lingkungan setempat dimana adanya aliran air yang cukup deras disepanjang dinding. Oleh karena itu perlu digunakannya pondasi dalam. Dalam mendesain dinding penahn tanah, hal yang harus diketahui adalah sifat-sifat tanah berupa berat satuan volume $(\gamma \mathrm{s})$, sudut geser dalam $(\gamma)$ dan kohesi $(C)$ untuk tanah di belakang dinding dan tanah di bawah dasar lantai (Kalalo, 2017).

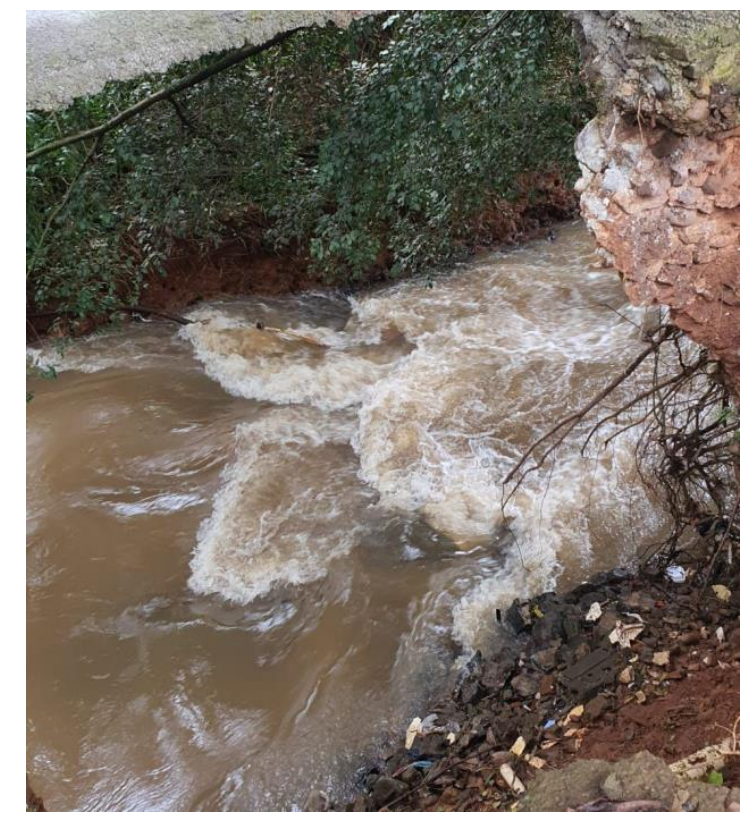

Gambar 2. Aliran air di sebelah dinding penahan tanah

Seiring dengan perkembangaann teknologi, munculah banyak software yang mendukung analisis dan perhitungan dinding penahan tanah dengan berbagai macam karakteristik dan parameter tanah. Salah satunya adalah $P-Y$ Wall buatan Texas, Amerka. Versi pertama dari P-Y Wall sendiri sudah rilis sejak tahun 1999 dan sekarang yang terbaru adalah versi ke-4 di tahun 2019. 
Pembahasan mengenai penulisan ini adalah mengenai analisis perbaikan desain untuk kerusakan dinding penahan tanah. Diambil beberapa variasi sebagai solusi yaitu bentuk desain dinding penahan tanah, posisi muka air tanah, dan jarak antar tiang.

1. Apa saja parameter penting yang digunakan sebagai dasar perencanaan dinding penahan tanah?

2. Apa saja gaya-gaya yang bekerja pada dinding penahan tanah ini?

3. Bagaimana permodelan dinding penahan tanah dengan $P-Y$ Wall?

4. Apakah desain dinding penahan tanah tersebut kuat untuk menahan beban yang bekerja?

Berdasarkan rumusan masalah yang telah disebutkan diatas, maka tujuan dari penelitian ini adalah menjawab rumusan masalah diatas yaitu:

1. Menjelaskan parameter-parameter penting yang digunakan untuk mendesain dinding penahan tanah.

2. Menjelaskan gaya-gaya yang bekerja pada dinding penahan tanah.

3. Memodelkan dinding penahan tanah dengan $P-Y$ Wall untuk mendapatkan hasil analisa.

4. Menjelaskan bagaimana desain tersebut bisa kuat menahan beban yang bekerja

\section{Dinding penahan tanah}

Dinding penahan tanah atau biasa disingkat DPT (Retaining Wall) adalah salah satu bangunan tanah yang berfungsi menstabilkan tanah pada kondisi tanah tertentu khususnya untuk areal lereng alam dan lereng buatan serta lereng akibat urugan tanah (Kalalo, 2017).

\section{Tiang beton}

Tiang beton adalah produk beton cetak. Tiang ini digunakan sebagai tiang untuk menyangga beban sekaligus menyalurkan beban ke dasar tanah. Tiang ini merupakan modifikasi baru dari tiang pancang konvensional. Salah satu keuntungannya adalah efisiensi waktu ketika pemasangannya. Selain itu, tiang ini juga sudah dilengkapi dengan tulangan besi sehingga bisa menjaga mutu dan kekuatannya.

\section{Teori rankine}

Teori tekanan tanah lateral yang dipakai pada PYWALL adalah Teori Rankine yang mengasumsikan bahwa:

1. Tidak ada adhesi atau friksi antara dinding dengan tanah (sebenernya friksi ada tapi sangat kecil sehingga dapat diabaikan).

2. Tekanan tanah lateral terbatas hanya untuk dinding vertikal dengan sudut $90^{\circ}$.

3. Kelongsoran (pada tanah urugan) dapat terjadi sebagai akibat dari pergeseran tanah yang ditentukan oleh sudut geser tanah $\left(\phi^{\prime}\right)$.

4. Tekanan lateral bervariasi linier terhadap kedalaman dan resultan tekanan yang berada pada 1/3 tinggi dinding, diukur dari dasar dinding.

5. Resultan gaya yang bekerja bersifat pararel terhadap permukaan urugan.

\section{N-spt koreksi}

Untuk tanah pasir, koreksi N-SPT dipakai bila N-SPT lapangan lebih dari 15 dengan rumus:

$$
N^{\prime}=15+(0,5 \times(N-15))
$$

dengan N' = N-SPT hasil koreksi dan N = N-SPT lapangan.

Berdasarkan SNI 4153:2008 didapat koreksi N-SPT yang digunakan adalah sebagai berikut:

$$
\begin{aligned}
& (N 1) 60=N M \times C N \times C E x C B \times C R \times C S \\
& C N=2,2 /\left(1,2+\left(\sigma^{\prime} v o / P a\right)\right.
\end{aligned}
$$

dengan $(\mathrm{N} 1)_{60}=$ nilai SPT yang dikoreksi terhadap pengaruh efisiensi tenaga $60 \%, \mathrm{~N}_{\mathrm{M}}=$ hasil uji SPT di lapangan, $\mathrm{C}_{\mathrm{N}}=$ faktor koreksi terhadap tegangan vertikal efektif (nilainya $\leq 1,70$ ), $\mathrm{C}_{\mathrm{E}}=$ faktor koreksi terhadap rasio tenaga palu (Tabel 1), $C_{B}=$ faktor koreksi terhadap diameter bor (Tabel 1), $C_{R}=$ faktor koreksi untuk panjang batang SPT (Tabel 1), $\mathrm{C}_{\mathrm{S}}=$ koreksi terhadap tabung contoh (samplers) dengan atau tanpa pelapis (liner) $($ Tabel 1$), \sigma^{\prime}{ }_{\text {vo }}=$ tegangan vertikal efektif $(\mathrm{kPa})$, dan $\mathrm{Pa}=100 \mathrm{kPa}$. 
Tabel 1. Koreksi-koreksi yang digunakan dalam uji SPT

\begin{tabular}{|c|c|c|c|}
\hline Faktor & Jenis Alat & Parameter & Koreksi \\
\hline $\begin{array}{l}\text { Tegangan vertikal } \\
\text { efektif }\end{array}$ & & $\mathrm{C}_{\mathrm{N}}$ & $2,2 /\left(1,2+\left(\sigma^{\prime}{ }_{v o} / \mathrm{Pa}\right)\right)$ \\
\hline $\begin{array}{l}\text { Tegangan vertikal } \\
\text { efektif }\end{array}$ & & $\mathrm{C}_{\mathrm{N}}$ & $\mathrm{C}_{\mathrm{N}} \leq 1,7$ \\
\hline Rasio tenaga & $\begin{array}{l}\text { Palu donat (Donut } \\
\text { hammer) }\end{array}$ & $\mathrm{C}_{\mathrm{E}}$ & 0,5 s.d 1,0 \\
\hline Rasio tenaga & $\begin{array}{l}\text { Palu pengaman (Safety } \\
\text { hammer) }\end{array}$ & $\mathrm{C}_{\mathrm{E}}$ & 0,7 s.d 1,2 \\
\hline Rasio tenaga & $\begin{array}{l}\text { Palu otomatik } \\
\text { (Automatic-trip Donut- } \\
\text { type hammer) }\end{array}$ & $\mathrm{C}_{\mathrm{E}}$ & 0,8 s.d 1,3 \\
\hline Diameter bor & 65 s.d $115 \mathrm{~mm}$ & $\mathrm{C}_{\mathrm{B}}$ & 1,0 \\
\hline Diameter bor & $150 \mathrm{~mm}$ & $\mathrm{C}_{\mathrm{B}}$ & 1,05 \\
\hline Diameter bor & $200 \mathrm{~mm}$ & $\mathrm{C}_{\mathrm{B}}$ & 1,15 \\
\hline Panjang batang & $<3 \mathrm{~m}$ & $\mathrm{C}_{\mathrm{R}}$ & 0,75 \\
\hline Panjang batang & $3 \mathrm{s.d} 4 \mathrm{~m}$ & $\mathrm{C}_{\mathrm{R}}$ & 0,8 \\
\hline Panjang batang & 4 s.d $6 \mathrm{~m}$ & $\mathrm{C}_{\mathrm{R}}$ & 0,85 \\
\hline Panjang batang & $6 \mathrm{~s} . \mathrm{d} 10 \mathrm{~m}$ & $\mathrm{C}_{\mathrm{R}}$ & 0,95 \\
\hline Panjang batang & 10 s.d. $30 \mathrm{~m}$ & $\mathrm{C}_{\mathrm{R}}$ & 1,0 \\
\hline Pengambilan contoh & Tabung standar & $\mathrm{C}_{\mathrm{S}}$ & 1,0 \\
\hline Pengambilan contoh & $\begin{array}{l}\text { Tabung dengan pelapis } \\
\text { (liner) }\end{array}$ & $\mathrm{C}_{\mathrm{S}}$ & 1,1 s.d 1,3 \\
\hline
\end{tabular}

(Sumber: Youd, T.L. \& Idriss, I.M., 2001)

\section{Undrained shear strength $(\mathrm{Cu})$}

Undrained shear strength adalah kuat geser tanah pada saat tanah dalam keadaan konstan. Kuat geser tanah adalah gaya perlawanan yang dilakukan oleh butir-butir tanah terhadap desakan atau tarikan. Oleh karena itu, bila tanah mengalami pembebanan akan ditahan oleh (Hardiyatmo, 2002):

1. Kohesi tanah yang bergantung pada jenis tanah dan kepadatannya, tetapi tidak tergantung dari tegangan normal yang bekerja pada bidang geser,

2. Gesekan antara butir-butir tanah yang besarnya berbanding lurus dengan tegangan normal pada bidang gesernya.

Nilai $C u$ diambil berdasarkan korelasi dari tabel dan grafik dibawah ini.

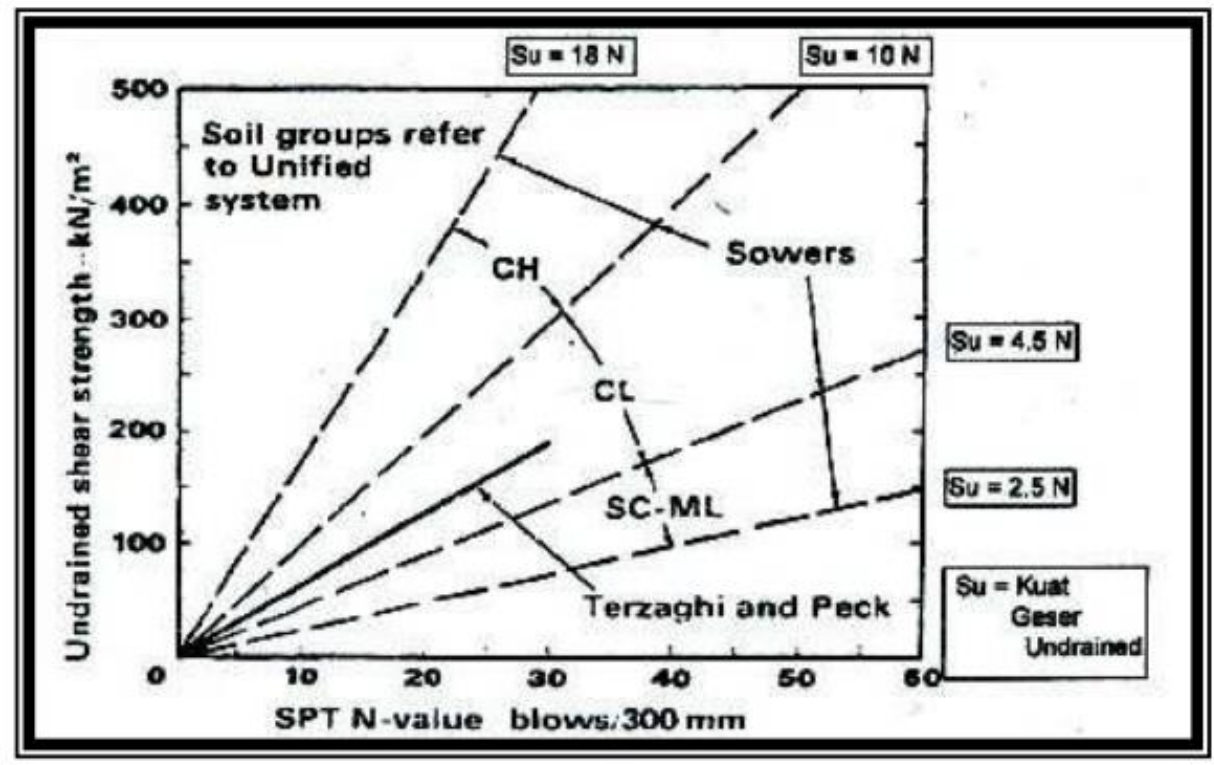

Gambar 3. Korelasi Nilai N-SPT dan Su (Sumber: Terzaghi dan Peck, 1967) 
Tabel 2. Korelasi N-SPT dengan $\mathrm{Cu}$

\begin{tabular}{ccc}
\hline Konsistensi & N-SPT & $\mathrm{Cu}\left(\mathrm{kN} / \mathrm{m}^{2}\right)$ \\
\hline Sangat Lunak & $0-2$ & $<12$ \\
Lunak & $2-4$ & $12-25$ \\
Sedang & $4-8$ & $25-50$ \\
Kaku & $8-15$ & $50-100$ \\
Sangat Kaku & $15-30$ & $100-200$ \\
Keras & $>30$ & $>200$ \\
\hline
\end{tabular}

(Sumber: Terzaghi dan Peck, 1967)

\section{Nilai unit weight $(\gamma)$ dan friction angle $(\phi)$}

Berat jenis tanah adalah perbandingan antara masa total tanah dengan total volume yang hanya termasuk terhadap berat air dan udara. Sudut geser dalam adalah sudut yang terbentuk dari hubungan tegangan normal dan tegangan geser pada material dalam tanah. Nilai unit weight dan friction angle diambil dari korelasi tabel-tabel dibawah ini.

Tabel 3. Korelasi jenis tanah dengan nilai unit weight

\begin{tabular}{ccc}
\hline Jenis Tanah & $\gamma_{\text {sat }}\left(\mathrm{kN} / \mathrm{m}^{3}\right)$ & $\gamma_{\text {dry }}\left(\mathrm{kN} / \mathrm{m}^{3}\right)$ \\
\hline Gravel & $20-22$ & $15-17$ \\
Sand & $18-20$ & $13-16$ \\
Silt & $18-20$ & $14-18$ \\
Clay & $16-22$ & $14-21$ \\
\hline
\end{tabular}

(Sumber: Budhu, 2000)

Tabel 4. Korelasi jenis tanah dan nilai N-SPT dengan friction angle

\begin{tabular}{cccc}
\hline Soil & Density/Consistency & N-SPT & $\phi$ \\
\hline \multirow{4}{*}{ Sands } & Very Loose & $0-4$ & $<30$ \\
& Loose & $5-10$ & $30-35$ \\
& Medium Dense & $11-30$ & $35-38$ \\
& Dense & $31-50$ & $38-41$ \\
& Very Dense & $>50$ & $41-44$ \\
Cohesive & Very Soft & $0-2$ & \\
Soils & Firm & $2-8$ & NA \\
& Stiff & $9-15$ & \\
\hline
\end{tabular}

(Sumber: www.scribd.com)

\section{Regangan (650) dan parameter modulus $k$ dalam pywall}

Regangan (strain) didefinisikan sebagai perubahan relatif ukuran atau bentuk suatu benda yang mengalami tegangan. Untuk program $P-Y$ Wall nilai $\epsilon_{50}$ dan parameter modulus $\mathrm{K}$ mengikuti tabel dibawah ini.

Tabel 5. Parameter modulus tanah k untuk sands

\begin{tabular}{cccc}
\hline Relative Density & Loose & Medium & Dense \\
\hline \multirow{2}{*}{ Submerged Sand } & $20 \mathrm{lb} / \mathrm{in}^{3}$ & $60 \mathrm{lb} / \mathrm{in}^{3}$ & $125 \mathrm{lb} / \mathrm{in}^{3}$ \\
& $5430 \mathrm{KPa} / \mathrm{m}$ & $16300 \mathrm{KPa} / \mathrm{m}$ & $33900 \mathrm{KPa} / \mathrm{m}$ \\
\multirow{2}{*}{ Sand Above WT } & $25 \mathrm{lb} / \mathrm{in}^{3}$ & $90 \mathrm{lb} / \mathrm{in}^{3}$ & $225 \mathrm{lb} / \mathrm{in}^{3}$ \\
& $6790 \mathrm{KPa} / \mathrm{m}$ & $24430 \mathrm{KPa} / \mathrm{m}$ & $61000 \mathrm{KPa} / \mathrm{m}$ \\
\hline
\end{tabular}

Tabel 6. Parameter modulus tanah k untuk clays

\begin{tabular}{ccc}
\hline Clay Type & $\begin{array}{c}\text { Avg. Undrained Shear } \\
\text { Sterngth }(\mathrm{Cu})\end{array}$ & $\begin{array}{c}\text { K for Static } \\
\text { Condition }\end{array}$ \\
\hline Soft & $12-24 \mathrm{KPa}$ & $8140 \mathrm{KPa} / \mathrm{m}$ \\
Medium & $24-48 \mathrm{KPa}$ & $27150 \mathrm{KPa} / \mathrm{m}$ \\
Stiff & $48-96 \mathrm{KPa}$ & $136000 \mathrm{KPa} / \mathrm{m}$ \\
Very Stiff & $96-192 \mathrm{KPa}$ & $271000 \mathrm{KPa} / \mathrm{m}$ \\
Hard & $192-383 \mathrm{KPa}$ & $543000 \mathrm{KPa} / \mathrm{m}$ \\
\hline
\end{tabular}


Tabel 7. Nilai $\epsilon_{50}$ untuk tanah clay

\begin{tabular}{cc}
\hline Consistency of Clay & $\mathrm{E}_{50}$ \\
\hline Soft & 0.020 \\
Medium & 0.010 \\
Stiff & 0.005 \\
\hline
\end{tabular}

Tabel 8. Nilai $\epsilon_{50}$ untuk tanah stiff clays

\begin{tabular}{cc}
\hline Average Undrained Shear Strength $(\mathrm{kPa})$ & $\mathrm{E}_{50}$ \\
\hline $50-100$ & 0.007 \\
$100-200$ & 0.005 \\
$300-400$ & 0.004 \\
\hline
\end{tabular}

\section{Defleksi izin}

Untuk defleksi sesuai dengan SNI 8460:2017 terdapat syarat batasan deformasi lateral izin dinding penahan tanah yang ditentukan oleh kondisi tanah, kedalaman galian serta jarak dan kondisi gedung terdekat yang besarnya ditentukan oleh tabel dibawah ini.

Tabel 9. Batas maksimum deformasi lateral dinding

\begin{tabular}{|c|c|c|c|c|}
\hline $\begin{array}{l}\text { Batas Maksimum Deformasi Lateral } \\
\text { pada Dinding }\end{array}$ & \multicolumn{4}{|c|}{$\begin{array}{l}\text { Lokasi Gedung dan Infrastruktur Eksisting Terdekat } \\
\text { Zona } 3(\mathrm{x} / \mathrm{H}>2)\end{array}$} \\
\hline $\begin{array}{l}\text { Keterangan: } \\
\mathrm{x}=\text { jarak dari batas galian, } \\
\mathrm{H}=\text { kedalaman galian, } \\
\delta \mathrm{w}=\text { defleksi dinding }\end{array}$ & $\begin{array}{c}\text { Zona } 1 \\
(\mathrm{x} / \mathrm{H}<1)\end{array}$ & $\begin{array}{c}\text { Zona } 2 \\
(1 \leq \mathrm{x} / \mathrm{H} \leq 2)\end{array}$ & $\begin{array}{l}\text { Tanah } \\
\text { Tipe A }\end{array}$ & $\begin{array}{l}\text { Tanah } \\
\text { Tipe B }\end{array}$ \\
\hline Batas izin maksimum deformasi $(\delta w / H)$ & $0,5 \%$ & $0,7 \%$ & $0,7 \%$ & $1,0 \%$ \\
\hline
\end{tabular}

(Sumber: SNI 8460:2017)

Keterangan:

a) Tanah Tipe A meliputi: tanah lempung dan lanau overconsolidated (over-consolidated stiff clays dan silts), tanah residual (residual soils), dan tanah pasir dengan kepadatan sedang sampai dengan padat (medium to dense sands).

b)Tipe Tanah B meliputi: tanah lempung dan lanau lunak (soft clays, silts), tanah organik (organic soils) dan tanah timbunan tidak terpadatkan (loose fills).

Dengan demikian, batas maksimum deforasi lateral dinding adalah sebesar 10,6 cm. Variabel x menjukkan jarak ke gedung terdekat sedangkan dilokasi tidak terdapat gedung disekitarnya sehingga didapat nilai $\mathrm{x} / \mathrm{H}>2$.

\section{Spesifikasi Tiang Pancang}

Gambar 4. Spesifikasi Tiang Pancang

\section{JHS PILE STRENGTH STANDARD SPECIFICATION}

\begin{tabular}{|c|c|c|c|c|c|c|c|c|c|c|c|c|c|c|c|}
\hline \multirow[b]{2}{*}{ Size } & \multirow[b]{2}{*}{$\begin{array}{l}\text { Weight } \\
\mathrm{kg} / \mathrm{m}^{\prime}\end{array}$} & \multirow[b]{2}{*}{$\begin{array}{l}\text { Area } \\
\mathrm{cm}^{2}\end{array}$} & \multirow[b]{2}{*}{$\begin{array}{c}\text { Length } \\
\mathrm{m}\end{array}$} & \multirow[b]{2}{*}{$\begin{array}{l}\text { No. of } \\
\text { Strand }\end{array}$} & \multirow[b]{2}{*}{$\begin{array}{l}\text { Type of } \\
\text { Strand }\end{array}$} & \multirow{2}{*}{$\begin{array}{c}\text { Eff } \\
\text { Prestress } \\
\text { Mpa }\end{array}$} & \multicolumn{3}{|c|}{\begin{tabular}{c|c|} 
Axial load \\
Allowable Urt imate Nominal
\end{tabular}} & \multirow[b]{2}{*}{$\begin{array}{c}\text { Tension Uit. } \\
\qquad \mathrm{kN}\end{array}$} & \multirow{2}{*}{$\begin{array}{c}\text { Shear } \\
\text { Cap } \\
\mathrm{kN}\end{array}$} & \multirow{2}{*}{\begin{tabular}{|c|} 
Torsion \\
Cap \\
kNm
\end{tabular}} & \multicolumn{3}{|c|}{ Moment } \\
\hline & & & & & & & $\begin{array}{c}\text { Allowable } \\
\mathrm{kN}\end{array}$ & $\begin{array}{l}\text { Utimate } \\
\mathrm{kN}\end{array}$ & $\begin{array}{c}\text { Nominal } \\
\mathbf{k N}\end{array}$ & & & & \begin{tabular}{l|} 
Crack \\
kNom
\end{tabular} & $\begin{array}{l}P=0 \\
k N m\end{array}$ & $\begin{array}{c}M \max \\
\mathrm{kNm}\end{array}$ \\
\hline \multirow{4}{*}{$25 \times 25$} & \multirow{4}{*}{156.25} & \multirow{4}{*}{625} & $6-12$ & 4 & $3 / 8^{\prime \prime}$ & 3.67 & 794 & 1,292 & 1,615 & 338 & 137.49 & 5.03 & 19.95 & 31 & 50 \\
\hline & & & $6-14$ & 5 & $3 / 8^{4}$ & 4.58 & 779 & 1,307 & 1,634 & 422 & 145.03 & 5.03 & 22.34 & 35 & 50 \\
\hline & & & $6-15$ & 6 & $3 / 8^{\prime \prime}$ & 5.50 & 763 & 1,318 & 1,648 & 506 & 152.56 & \begin{tabular}{|l|l|}
5.03 \\
\end{tabular} & 24.72 & 39 & 50 \\
\hline & & & $6-16$ & 4 & $1 / 2^{\prime \prime}$ & 6.58 & 745 & 1,335 & 1,669 & 608 & 161.47 & 5.03 & 27.55 & 33 & 51 \\
\hline \multirow{4}{*}{$30 \times 30$} & \multirow{4}{*}{225.00} & \multirow{4}{*}{900} & $6-13$ & 4 & $3 / 8^{\prime \prime}$ & 2.55 & 1,171 & 1,835 & 2,294 & 338 & 192.43 & 8.70 & 29.43 & 43 & 85 \\
\hline & & & $6-14$ & 5 & $3 / 8^{\prime \prime}$ & 3.18 & 1,155 & 1,849 & 2,311 & 422 & 200.28 & 8.70 & 32.30 & 49 & 86 \\
\hline & & & $6-15$ & 6 & $3 / 8^{\prime \prime}$ & 3.82 & 1,140 & 1,864 & 2,330 & 506 & 208.12 & 8.70 & 35.16 & 56 & 86 \\
\hline & & & $6-16$ & 4 & $1 / 2^{\prime \prime}$ & 4.57 & 1,121 & 1,881 & 2,351 & 608 & 217.40 & 8.70 & 38.55 & 61 & 87 \\
\hline \multirow{4}{*}{$35 \times 35$} & \multirow{4}{*}{306.25} & \multirow{4}{*}{1,225} & $6 \cdot 14$ & 5 & $3 / 8^{\prime \prime}$ & 2.34 & 1,600 & 2,491 & 3,114 & 422 & 265.82 & 13.81 & 45.25 & 61 & 136 \\
\hline & & & 6.15 & 6 & $3 / 8^{\prime \prime}$ & 2.34 & 1,585 & 2,505 & 3,131 & 506 & 273.89 & \begin{tabular}{|l|}
13.81 \\
\end{tabular} & 48.59 & 71 & 136 \\
\hline & & & $6 \cdot 16$ & 4 & $1 / 2^{n}$ & 3.36 & 1,567 & 2,522 & 3,153 & 608 & 283.43 & 13.81 & 52.54 & 83 & 137 \\
\hline & & & $6-17$ & 5 & $1 / 2^{\prime \prime}$ & 4.20 & 1,539 & 2,548 & 3,185 & 760 & 297.93 & 13.81 & 58.55 & 98 & 138 \\
\hline \multirow{4}{*}{$40 \times 40$} & \multirow{4}{*}{400.00} & \multirow{4}{*}{1,600} & $6-14$ & 4 & $1 / 2^{n}$ & 2.57 & 2,080 & 3,263 & 4,079 & 608 & 359.80 & 20.61 & 70.04 & 105 & 204 \\
\hline & & & $6 \cdot 16$ & 5 & $1 / 2^{n}$ & 3.21 & 2,052 & 3,289 & 4,111 & 760 & 374.59 & 20.61 & 76.89 & 121 & 205 \\
\hline & & & $6-18$ & 6 & $1 / 2^{\prime \prime}$ & 3.86 & 2,025 & 3,314 & 4,143 & 911 & 389.38 & 20.61 & 83.75 & 137 & 206 \\
\hline & & & $6 \cdot 19$ & 7 & $1 / 2^{\prime \prime}$ & 4.50 & 1,997 & 3,340 & 4,175 & 1,063 & 404.18 & 20.61 & 90.61 & 153 & 208 \\
\hline \multirow{4}{*}{$45 \times 45$} & \multirow{4}{*}{506.25} & \multirow{4}{*}{2,025} & $6-16$ & 5 & $1 / 2^{\prime \prime}$ & 2.54 & 2,634 & 4,127 & 5,159 & 760 & 461.66 & 29.35 & 99.24 & 141 & 291 \\
\hline & & & $6-17$ & 6 & $1 / 2^{*}$ & 3.05 & 2,607 & 4,152 & 5,190 & 911 & 476.69 & 29.35 & 106.95 & 162 & 292 \\
\hline & & & $6-18$ & 7 & $1 / 2^{\prime \prime}$ & 3.56 & 2,579 & 4,178 & 5,223 & 1,063 & 491.71 & 29.35 & \begin{tabular}{|c|}
114.67 \\
\end{tabular} & 184 & 294 \\
\hline & & & $6 \cdot 20$ & 8 & $1 / 2^{\prime \prime}$ & 4.06 & 2,551 & 4,203 & 5,254 & 1,215 & 506.74 & 29.35 & 122.38 & 205 & 296 \\
\hline \multirow{4}{*}{$50 \times 50$} & & & $6 \cdot 16$ & 6 & $1 / 2^{\prime \prime}$ & 2.47 & 3,257 & 5,090 & 6,363 & 911 & 574.44 & 40.26 & 134.65 & 189 & 399 \\
\hline & 625.00 & 2500 & $6 \cdot 18$ & 7 & $1 / 2^{n}$ & 2.88 & 3,229 & 5,115 & 6,394 & 1,063 & 589.66 & 40.26 & 143.22 & 216 & 401 \\
\hline & & 2,500 & $6 \cdot 19$ & 8 & $1 / 2^{\prime \prime}$ & 3.29 & 3,202 & 5,141 & 6,426 & 1,215 & 604.88 & 40.26 & 151.79 & 243 & 403 \\
\hline & & & $6 \cdot 20$ & 9 & $1 / 2^{2}$ & 3.70 & 3,147 & 5,166 & 6,458 & 1,367 & 620.09 & 40.26 & 160.36 & 268 & 405 \\
\hline
\end{tabular}

(Sumber: www.rumahmaterial.com) 


\section{METODE PENELITIAN}

Dalam perhitungan ini menggunakan closed-form solution. Bentuk tertutup berpotensi memberi pemahaman yang lebih baik tentang bagaimana variabel desain yang berbeda memengaruhi kinerja. Metode ini tidak bisa membagi elemen menjadi lebih kecil, tidak seperti Finite Element.

\section{Metodologi dan diagram alir penelitian}

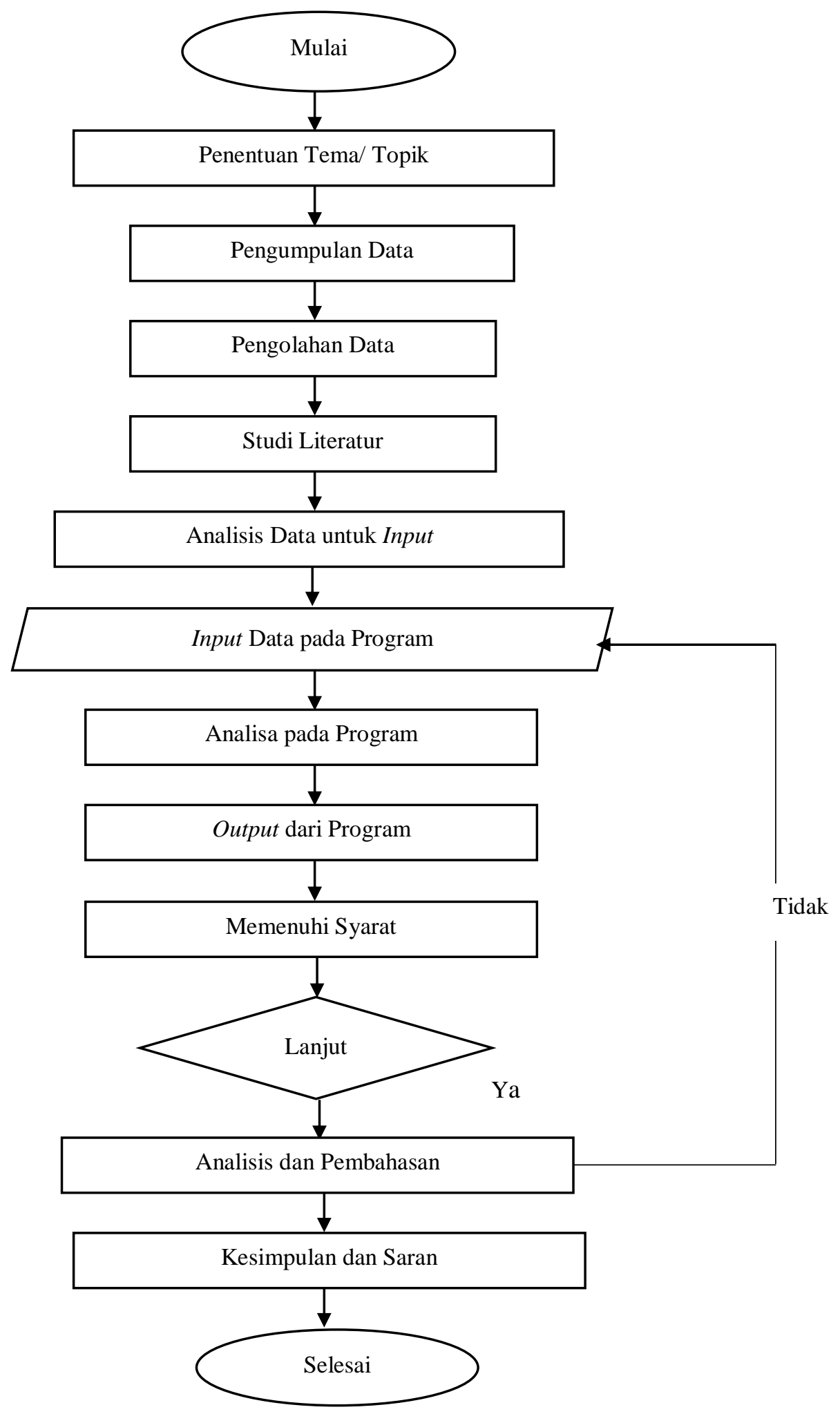

Gambar 5. Diagram alir penelitian 


\section{Pengumpulan data}

Data tanah yang akan dipakai pada analisis adalah data tanah hasil penyelidikkan tanah dengan metode N-SPT sehingga didapatkan Boring Log. Hasil yang diperoleh berupa kedalaman tanah keras, klasifikasi tanah, dan nilai N-SPT untuk setiap lapisan tanah.

\section{Pengolahan data}

Program $P-Y$ Wall mempertimbangkan efek interaksi struktur tanah dengan menggunakan model kolom balok umum dan menganalisis perilaku dinding penahan yang fleksibel atau dinding tiang pancang/bor dengan atau tanpa tieback atau sistem bracing. Program ini akan menghitung defleksi dinding/tiang, gaya geser, dan momen lentur (Wang and Arrellaga). Parameter input terdiri dari ukuran/dimensi dinding penahan, sifat struktural elemen dinding, kondisi batas yang diterapkan pada dinding, kurva tanah, satuan berat tanah, parameter kekuatan tanah, dan lokasi muka air tanah. Setelah semua parameter yang dibutuhkan dimasukkan dalam program, maka program akan menganalisis data-data tersebut. Program P-Y Wall akan menghasilkan nilai defleksi, momen, dan geser.

\section{Parameter input}

Parameter input terdiri dari ukuran/dimensi dinding penahan, sifat struktural elemen dinding, kondisi batas yang diterapkan pada dinding oleh tieback atau sistem penguat lainnya, kurva tanah, satuan berat tanah, parameter kekuatan tanah, dan lokasi muka air tanah.

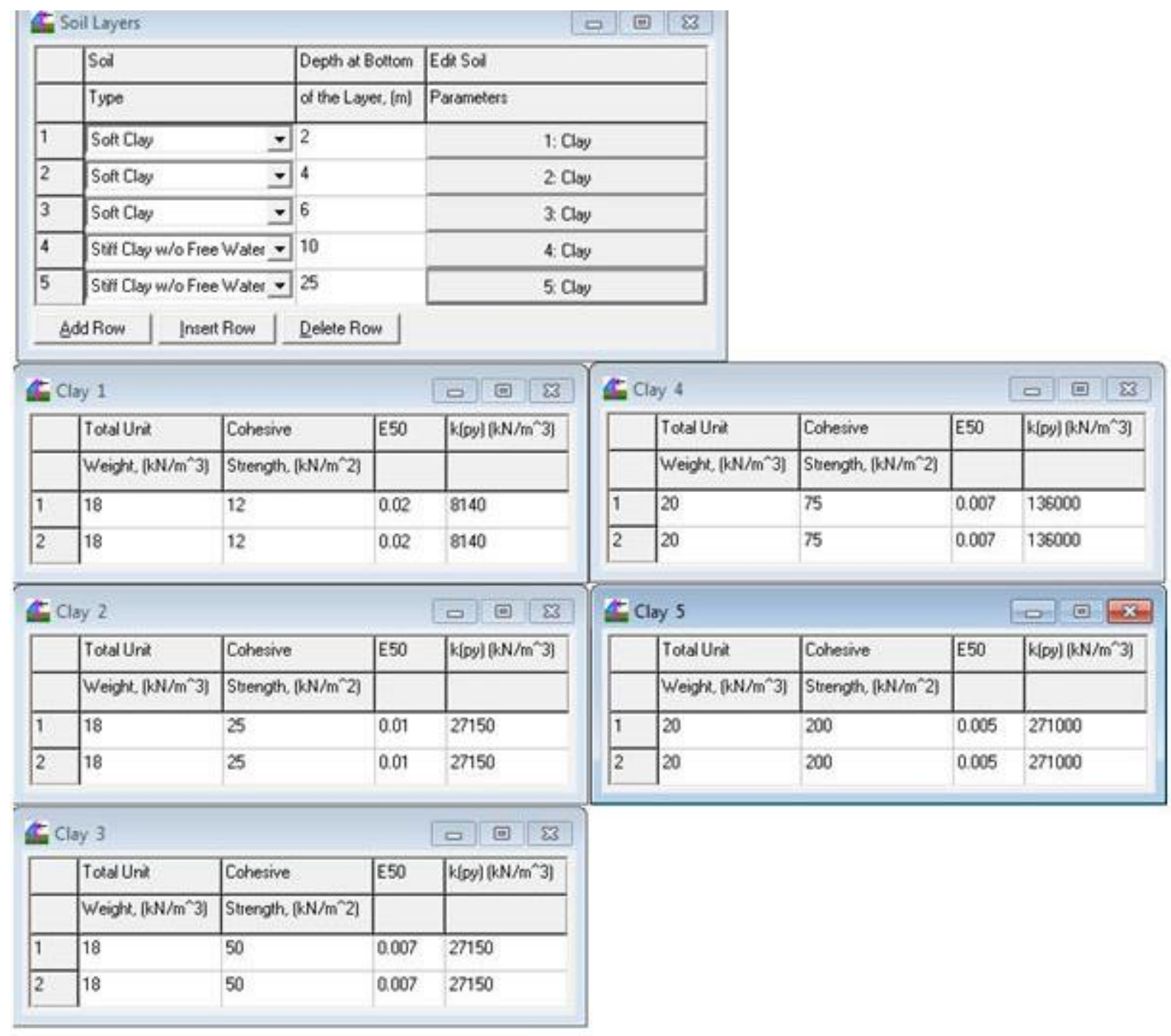

Gambar 6. Parameter input berupa data tanah 


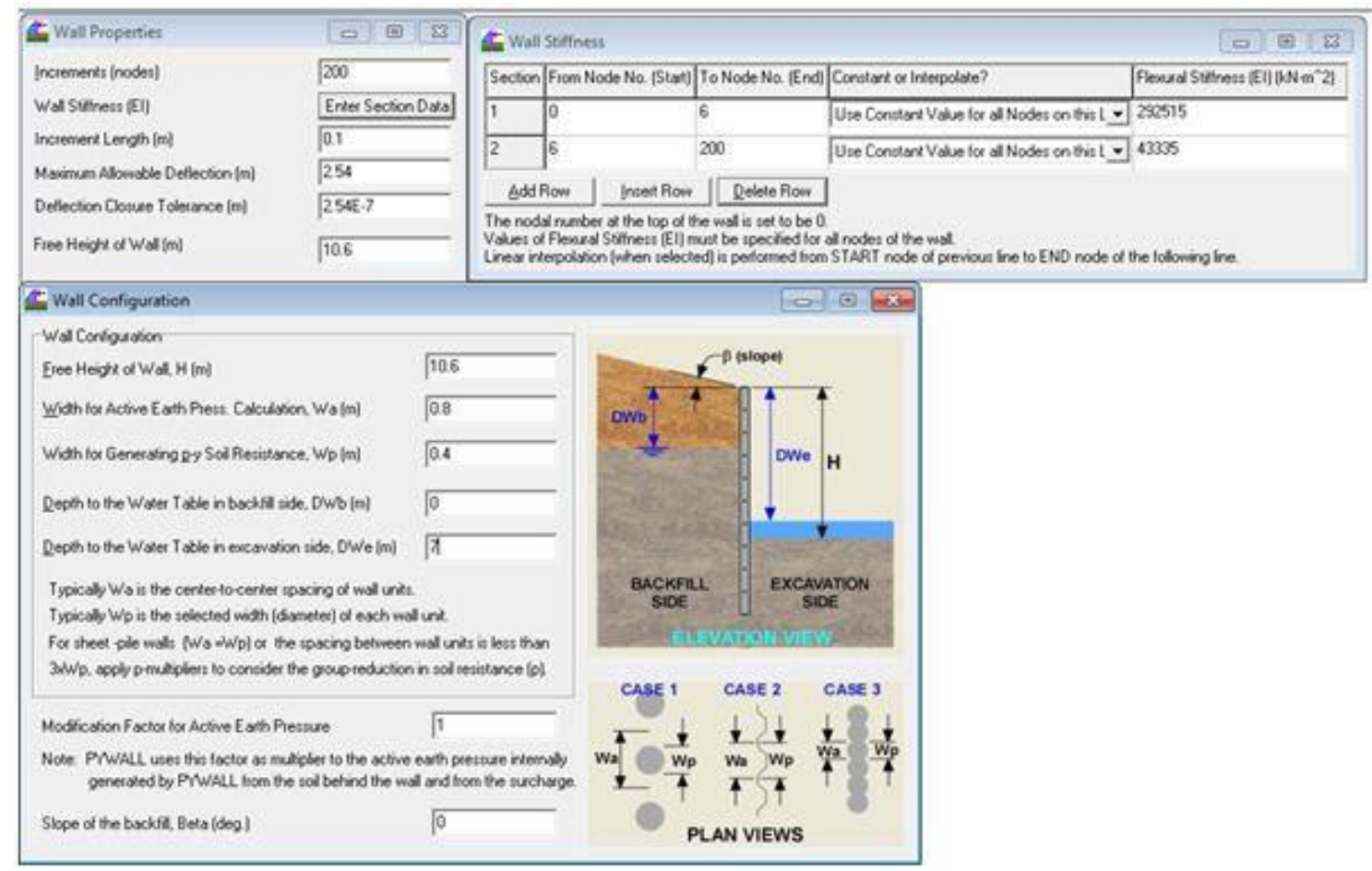

Gambar 7. Parameter input berupa data dinding penahan tanah

\section{HASIL DAN PEMBAHASAN}

Analisis akan dilakukan terhadap model dinding penahan tanah dengan metode closed form solution dengan bantuan program $P Y$-WALL. Dalam penulisan ini dibuat variasi yang berhubungan dengan jarak antar tiang dan besarnya L1 dan L2. L1 menunjukkan panjang tiang bebas dan L2 menunjukkan panjang tiang yang masuk ke dalam tanah. Berikut adalah ilustrasi panjang L1 dan L2 di lapangan pada gambar 7. Variasi desain yang dibuat seperti yang disajikan dalam tabel 10 .

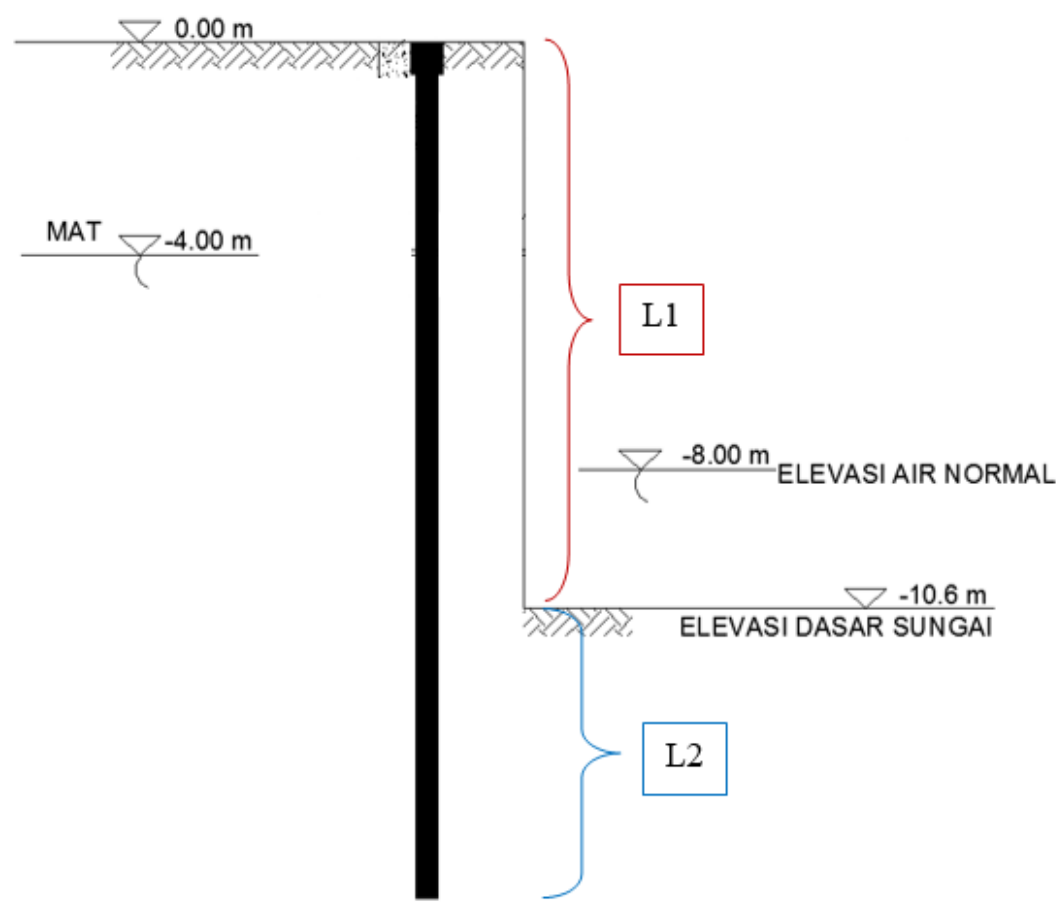

Gambar 8. Model dinding penahan tanah 
Tabel 10. Variasi desain

\begin{tabular}{cccc}
\hline No. Variasi & Jarak Antar Tiang $(\mathrm{cm})$ & L1 $(\mathrm{m})$ & L2 $(\mathrm{m})$ \\
\hline Variasi 1A & $2 \mathrm{D}=100$ & 10,6 & 2,4 \\
Variasi 2A & & 3,4 \\
Variasi 3A & & 4,4 \\
Variasi 4A & & 5,4 \\
Variasi 5A & & 6,4 \\
Variasi 6A & & 7,4 \\
Variasi 7A & & 8,4 \\
Variasi 8A & & 9,4 \\
Variasi 1B & & 2,4 \\
Variasi 2B & 10,6 & 3,4 \\
Variasi 3B & & 4,4 \\
Variasi 4B & & 5,4 \\
Variasi 5B & & 6,4 \\
Variasi 6B & & 7,4 \\
Variasi 7B & & 8,4 \\
Variasi 8B & & 9,4 \\
\hline
\end{tabular}

\section{Data tiang}

Dinding penahan tanah menggunakan tiang dengan mutu K-500 ( $\mathrm{fc}^{\prime}=41,5 \mathrm{MPa}$ ) berbentuk persegi panjang dengan ukuran $50 \mathrm{~cm} \times 50 \mathrm{~cm}$. Berikut adalah perhitungan data yang digunakan dalam PYWALL. E adalah modulus elastisitas. I adalah inersia tiang. EI adalah kekakuan tiang.

$$
\begin{aligned}
& E=4700 \times \sqrt{f c^{\prime}} \\
& E=4700 \times \sqrt{41,5} \\
& E=30277,6320078 \mathrm{MPa}=30277632,0078 \mathrm{kPa} \\
& I=\frac{1}{12} \times b \times d^{3} \\
& I=\frac{1}{12} \times 0,5 \times 0,5^{3} \\
& I=0,005208 \mathrm{~m}^{4} \\
& E I=30277632,0078 \times 0,005208 \\
& E I=15768,4283 \mathrm{kN} / \mathrm{m}^{2}
\end{aligned}
$$

Jadi diperoleh kekakuan tiang (EI) sebesar $15768,4283 \mathrm{kN} / \mathrm{m}^{2}$.

\section{Data capping beam}

Dalam menganalisa tiang ini diperlukan adanya capping beam yang berfungsi sebagai pengikat tiang yang satu dengan yang lainnya. Dimensi yang digunakan ada 2 variasi yaitu bergantung pada jarak antar tiang. Berikut adalah perhitungan data yang digunakan dalam PYWALL:

1. Capping Beam $100 \mathrm{~cm}$ x $60 \mathrm{~cm}$

$$
\begin{aligned}
& E=4700 \times \sqrt{f c^{\prime}} \\
& E=4700 \times \sqrt{41,5} \\
& E=30277,6320078 \mathrm{MPa}=30277632,0078 \mathrm{kPa} \\
& I=\frac{1}{12} \times b \times d^{3} \\
& I=\frac{1}{12} \times 1 \times 0,6^{3} \\
& I=0,018 \mathrm{~m}^{4}
\end{aligned}
$$




$$
\begin{aligned}
& E I=30277632,0078 \times 0,018 \\
& E I=544997,361 \mathrm{kN} / \mathrm{m}^{2}
\end{aligned}
$$

2. Capping Beam $75 \mathrm{~cm} \times 60 \mathrm{~cm}$

$$
\begin{aligned}
& I=\frac{1}{12} \times b \times d^{3} \\
& I=\frac{1}{12} \times 0,75 \times 0,6^{3} \\
& I=0,0135 \mathrm{~m}^{4} \\
& E I=30277632,0078 \times 0,0135 \\
& E I=408748,0321 \mathrm{kN} / \mathrm{m}^{2}
\end{aligned}
$$

Jadi, diperoleh kekakuan capping beam untuk jarak $100 \mathrm{~cm}$ adalah 544997,361 kN/m² dan jarak $75 \mathrm{~cm}$ adalah $408748,0321 \mathrm{kN} / \mathrm{m}^{2}$.

\section{Rangkuman tabel parameter tanah}

Tabel 11. Parameter tanah PYWALL

\begin{tabular}{cccccccc}
\hline $\begin{array}{c}\text { Kedalaman } \\
(\mathrm{m})\end{array}$ & $\begin{array}{c}\text { Jenis } \\
\text { Tanah }\end{array}$ & N-SPT & $\gamma\left(\mathrm{kN} / \mathrm{m}^{3}\right)$ & $\mathrm{Cu}(\mathrm{kPa})$ & & $\begin{array}{c}\mathrm{K} \\
(\mathrm{kPa} / \mathrm{mm})\end{array}$ & $\Phi\left(^{0}\right)$ \\
\hline $0-6$ & ML & 6 & 16 & 27 & 0.01 & 27150 & - \\
$6-8$ & ML & 12 & 18 & 54 & 0.005 & 136000 & - \\
$8-12$ & $\mathrm{CH}$ & 25 & 20 & 170 & 0.005 & 271000 & - \\
$12-16$ & $\mathrm{SW}$ & 33 & 20 & - & - & 33900 & 41 \\
$16-20$ & ML & 33 & 20 & 200 & 0.005 & 543000 & - \\
\hline
\end{tabular}

\section{Rangkuman hasil analisis variasi}

Tabel 12. Rangkuman defleksi dan momen tiap variasi

\begin{tabular}{ccccc}
\hline No. & $\begin{array}{c}\text { Jarak Antar } \\
\text { Tiang }(\mathrm{cm})\end{array}$ & $\begin{array}{c}\text { Panjang Tiang } \\
(\mathrm{m})\end{array}$ & Defleksi $(\mathrm{cm})$ & Momen $(\mathrm{kN} / \mathrm{m})$ \\
\hline Variasi 1A & 75 & 13 & 24 & 195 \\
Variasi 2A & & 14 & 11 & 300 \\
Variasi 3A & & 15 & 9,05 & 320 \\
Variasi 4A & & 16 & 8,96 & 320 \\
Variasi 5A & & 17 & 8,96 & 320 \\
Variasi 6A & & 18 & 8,95 & 320 \\
Variasi 7A & & 19 & 8,95 & 320 \\
Variasi 8A & & 13 & 8,95 & 320 \\
Variasi 1B & 100 & 14 & 33 & 260 \\
Variasi 2B & & 15 & 14,8 & 405 \\
Variasi 3B & & 16 & 12,2 & 430 \\
Variasi 4B & & 17 & 12,1 & 430 \\
Variasi 5B & & 18 & 12 & 430 \\
Variasi 6B & 19 & 12 & 430 \\
Variasi 7B & & 20 & 12 & 430 \\
Variasi 8B & & & 12 & 430 \\
\hline
\end{tabular}

\section{Pemilihan variasi}

Analisa intensif yang dilakukan dan berhasil mendapat hal yang tidak biasa/ jarang terjadi namun bisa dipertanggungjawabkan dimana dalam kondisi tanah tertentu amat mungkin bisa dihasilkan besarnya nilai L2 yang lebih kecil daripada L1. Patut dicatat bahwa temuan ini terbilang tidak lazim dalam arti kata biasanya L2 sama dengan atau lebih besar dari L1. L1 yang dimaksudkan disini adalah panjang tiang bebas dan L2 adalah panjang tiang yang menembus permukaan tanah. Jika kita lihat nilai L1 adalah 10,8 m dan nilai L2 berkisar antara 4,2 m hingga $9,2 \mathrm{~m}$. 

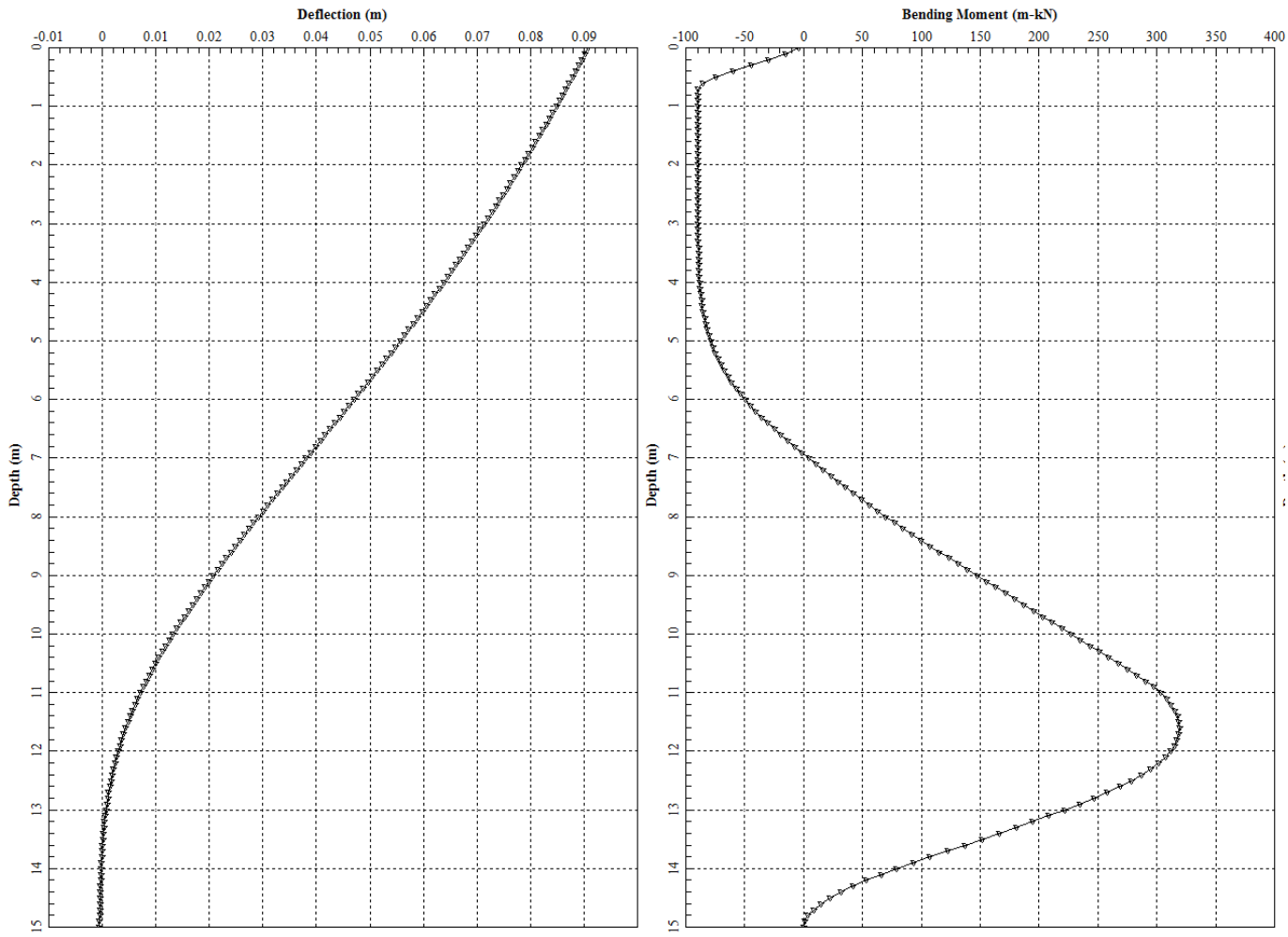

Gambar 9. Grafik defleksi dan momen variasi 3A

Berdasarkan hasil output diatas dapat diambil variasi terbaik untuk desain dinding penahan tanah ini adalah Variasi 3A yaitu dengan jarak antar tiang $75 \mathrm{~cm}$ dan panjang tiang $15 \mathrm{~m}$. Artinya nilai L1 sebesar 10,8 m dan nilai L2 sebesr 4,2 m. Hal ini mungkin terjadi mengingat tanah sudah sangat keras sejak kedalaman $12 \mathrm{~m}$.

Variasi 3A ini dipilih karena dilihat dari nilai defleksi momen yang berangsur-angsur sama atau hamper konstan yang menandakan bahwa sudah dalam kondisi terbaik untuk menahan beban lateral yang bekerja yaitu sebesar $9,05 \mathrm{~cm}$.

Nilai momen yang didapat untuk variasi 3A adalah $320 \mathrm{kN} / \mathrm{m}$. Berdasarkan Tabel 10 tentang Spesifikasi Tiang Pancang, didapatkan nilai momen $399 \mathrm{kN} / \mathrm{m}$ untuk tiang dengan dimensi $50 \mathrm{~cm}$ x $50 \mathrm{~cm}$. Maka dari itu, variasi 3A dapat memenuhi besarnya momen yang dapat ditahan oleh tiang yaitu memiliki nilai momen yang lebih kecil sebesar $320 \mathrm{kN} / \mathrm{m}$ sehingga memenuhi besarnya momen yang dapat ditahan oleh tiang.

Dilihat dari aspek lain, variasi 3A dapat menjadi pilihan berdasarkan pertimbangan mengenai kondisi di sekitar lokasi seperti berbatasan langsun dengan sungai yang alirannya cukup deras. Selain itu, kondisi tanah yaitu behavior tanah itu sendiri yang menunjukkan kemiringan ke arah sungai yang mungkin saja semakin lama semakin mengarah ke sungai. Maka, akan lebih aman jika menggunakan variasi yang memiliki defleksi dan momen maksimum yang sudah mencapai batas maksimum.

Dalam pelaksanaannya, melihat kondisi tanah yang awalnya tidak terlalu keras menjadi tiba-tiba keras yaitu disekitar kedalaman $12 \mathrm{~m}$, ada kemungkinan tiang akan sangat keras dan sangat sulit untuk dipancang. Oleh karena itu dapat menggunakan preboring terlebih dahulu sebelum pemacangan. Untuk penggunaan ukuran mata bor disesuaikan dengan ukuran tiang pancang, idealnya ukuran mata bor lebih kecil dari ukuran tiang pancang supaya didapatkan friksi tiang pancang yang maksimal.

Antar tiang akan menyisakan spacing yang bisa menyebabkan kelongsoran tanah. Maka dari itu, dibutuhkan semacam pelat beton untuk menahan dan menjaga tanah agar tetap dalam posisi. Adanya pelat beton tersebut membuat beban tanah terbagi rata setengah ke tiang sebelah kanan dan setengah lagi ke tiang sebelah kirinya. Analisis dua dimensi dalam penelitian ini tidak dapat memodelkan pelat beton tersebut namun sudah teranalisis dalam program.

Untuk kenaikkan MAT walaupun dalam penelitian ini tidak disinggung karena nilai MAT yang dipakai sudah aman yaitu di $-4.00 \mathrm{~m}$ dari MAT normal $-7.00 \mathrm{~m}$. Kondisi kritis MAT berada di $-6.00 \mathrm{~m}$. Andai kata naik dapat diatasi dengan penambahan weep holes yang berfungsi untuk menurukan ketinggian muka air tanah di belakang dinding. Untuk posisi pemasangan sebaiknya di kedalaman $-4.00 \mathrm{~m}$. 


\section{KESIMPULAN DAN SARAN}

\section{Kesimpulan}

Dari hasil analisis yang telah dilakukan, didapatkan beberapa hal yang dapat disimpulkan yaitu:

1. Parameter-parameter penting yang digunakan sebagai dasar perencanaan menggunakan program PYWALL ini adalah klasifikasi tanah, berat jenis tanah, N-SPT tanah, sudut geser dalam, regangan, koefisien $\mathrm{k}$ (konstanta PYWALL), undrained shear strength.

2. Gaya-gaya yang berkerja pada dinding penahan tanah ini adalah gaya lateral tanah yang menimbulkan tekanan aktif dan pasif.

3. Permodelan dinding penahan tanah berupa tiang dengan PYWALL menggunakan 16 variasi dengan memvariasikan jarak antar tiang serta kedalaman tiang.

4. Desain yang telah dibuat memenuhi syarat dari SNI dan juga brosur spesifikasi tiang dari JHS System sehingga mampu untuk menahan beban yang bekerja. Desain yang dimaksud adalah Variasi 3A dimana jarak antar tiang $75 \mathrm{~cm}$ serta kedalaman tiang $15 \mathrm{~m}$. Hal ini dapat dilihat dari nilai defleksi nya sebesar $9,05 \mathrm{~cm}$ lebih kecil daripada syarat defleksi defleksi maksimum sebesar $10,8 \mathrm{~cm}$. Untuk nilai momen variasi 2B adalah sebesar $320 \mathrm{kN} / \mathrm{m}$ lebih kecil dari batasan momen yang dapat ditahan oleh tiang sebesar $399 \mathrm{kN} / \mathrm{m}$. Hal yang tidak biasa didapat dari analisa ini adalah pada kondisi tanah tertentu amat mungkin bisa dihasilkan besarnya nilai L2 yang lebih kecil daripada L1. Patut dicatat bahwa temuan ini terbilang tidak lazim dalam arti kata biasanya L2 sama dengan atau lebih besar dari L1. Maksud disini adalah panjang tiang bebas dan L2 adalah panjang tiang yang menembus permukaan tanah.

\section{Saran}

Berdasarkan proses analisa yang telah dilakukan ditemukan beberapa masalah dan anomali baru yang belum dapat terpecahkan, oleh karena itu peneliti memberi saran untuk penelitian selanjutnya yaitu mengenai beberapa hal seperti:

1. Untuk penentuan parameter tanah akan jauh lebih baik menggunakan parameter yang benar-benar berasal dari test laboratorium tanah daripada korelasi data karena tentunya akan mempengaruhi keakuratan data.

2. Analisis dilakukan pada daerah aliran sungai dimana adanya pergerakan aliran air (hydrodynamic) sehingga perlu dilakuakan perhitungan hidrodinamik yang meliputi viskositas, kecepatan dan kedalam arus, dan sebagainya.

\section{DAFTAR PUSTAKA}

Badan Standarisasi Nasional. Persyaratan Perencanaan Geoteknik (SNI 8460:2017). Jakarta: BSN 2017. Badan Standarisasi Nasional.. Uji Penetrasi Lapangan dengan SPT (SNI 4153:2008). Jakarta: BSN, 2008. Budhu, M. Soil Mechanic and Foundation. John Wiley and Sons. USA: Inc, 2000.

Hardiyatmo, H. C. Mekanika Tanah I. Yogyakarta: Gajah Mada Universsity Press, 2002.

Kalalo, Melania. "Analisis Stabilitas Dinding Penahan Tanah (Studi Kasus: Sekitar Areal PT. Trakindo, Desa Maumbi. Kabupaten Minahasa Utara)." Jurnal Sipil Statik Vol. 5 No. 5 ISSN: 2337-6732 (2017): 285-294.

Terzaghi, K. dan Peck, R. (1967) Soil Mechanics in Engineering Practice. 2nd Edition, John Wiley, New York.

Wang, Shin Tower dan Jose A. Arrellaga. "Verification of Computer Program PYWALL As A Valid Tool For Design of Flexible Retaining Walls." PYWALL Validation Notes (2007).

Youd, T.L. dan Idriss, I.M. "Liquefaction Resistance of Soils : Summary Report from the 1996 NCEER Workshops on Evaluation of Liquefaction Resistance of Soil“, Journal of Geotechnical and Geoenvironmental Engineering , ASCE, April 2001, Vol. 127 No. 4 (2001): 297 -313.

Umass Lowell. scribd.com. 14.485 Capstone Design Module 4 - Geotechnical Engineering. 17 September 2019. 10 Maret 2020. <https://www.scribd.com/document/426219857/14-485capstonegeotechnicalmodule-pdf>

rumahmaterial.com. Tiang Pancang JHS Square Pile. 1 Mei 2015.20 Maret 2020. $<$ https://www.rumahmaterial.com/2015/05/tiang-pancang-jhs-square-pile.html> 
